\title{
La autodeterminación de los pueblos indígenas del Pacifico, Centro y Norte de Nicaragua
}

\author{
María Luisa Acosta
}

Los pueblos indígenas del Pacifico, Centro y Norte de Nicaragua han sufrido un arduo y forzado proceso de asimilación de la cultura dominante y el despojo de sus tierras colectivas, iniciado a partir de la conquista española, pasando por la época colonial y continuando con la fundación del Estado Nacional.

Los pueblos indígenas del Pacifico, Centro y Norte de Nicaragua actualmente se encuentran aglutinados en varias coordinadoras: la coordinadora Chorotega, cuya sede está en Mozonte, agrupa a los pueblos indígenas de Totogalpa, San Lucas, Telpaneca, Cusmapa y Mozonte; la coordinadora Diriangén, con sede en Matagalpa, reúne a los pueblos indígenas de Jinotega, Muy Muy, Sébaco y Matagalpa; la Coordinadora Agateyte, con sede en Sutiaba, aglutina a los pueblos indígenas de la Virgen de Hato del Viejo y Santa Rita de Tonalá, en Chinandega, y Sutiaba en León y Chinandega; la coordinadora Dirián Tenderí, con sede en Nindirí, congrega a los pueblos indígenas de Nindirí, Monimbó y San Juan de Oriente. La Coordinadora Nicarao, con sede en Rivas, agrupa a los pueblos indígenas de Nancimí, Ostional, Veracruz del Zapotal, Urbaité de las Pilas y Salinas de Nahualapa.

Cada uno de estos pueblos y comunidades mantiene su autonomía administrativa y política, ya que el aglutinarse en coordinadoras es expresión del ejercicio de su autodeterminación como pueblo. La autodeterminación les está reconocida entre los principios fundamentales de la nación nicaragüense, junto al pluralismo étnico y al reconocimiento a las distintas formas de propiedad, en el primer párrafo del Artículo 5 de la Constitución Política de Nicaragua; así como por La Declaración de las Naciones Unidas sobre los Derechos de los Pueblos Indígenas, aprobada con el voto del Estado de Nicaragua el 27 de septiembre del 2007.
Sin embargo, la invisibilidad en la cual se ha colocado a los pueblos indígenas del Pacifico, Centro y Norte de Nicaragua es una clara muestra de la violación a sus derechos humanos en cuanto a tener una identidad propia, manejar asuntos locales según sus costumbres y tradiciones, elegir sus propios representantes y gozar de una efectiva protección de la propiedad comunal. Por tanto, de esta forma se ha dejado de honrar la normativa constitucional que reconoce entre los principios fundamentales del Estado, la naturaleza multiétnica del pueblo nicaragüense.

\section{El Comité para la Eliminación de la Discriminación Racial de Naciones Unidas}

Los pueblos indígenas del Pacifico, Centro y Norte de Nicaragua continúan en la actualidad resistiendo a las políticas institucionales nacionales que ponen en peligro su subsistencia como pueblos. Por ejemplo, el informe del Estado de Nicaragua de 1995 ante el Comité para la Eliminación de la Discriminación Racial de Naciones Unidas, reportó que en el Pacífico, Centro y Norte de Nicaragua se habían asimilado culturalmente los indígenas. A principios del siglo XX se eliminó la casilla que determinaba la pertenencia étnica en el censo poblacional, y desde entonces se asumió la homogeneidad étnica de la población nicaragüense como mestiza.

A pesar de todo, la permanente resistencia de estos pueblos indígenas los ha preservado hasta la actualidad. Según el Censo de Población y Vivienda de $2005^{1}$, en Nicaragua existe una población de 443,847 personas auto identificadas como pertenecientes a una comunidad o pueblo indígena, lo que significa aproximadamente un $13 \%$ del total de la población del país; y solamente en el Pacífico, Centro y Norte, 11,113 personas se consideran nahoa-nicarao; 15, 240, cacaopera-matagalpa; 19, 949, xiu-sutiava, y 46,002,

VIII Censo de Población y IV de Viviendas, Población Características Generales. Volumen I. Pág. 181. Nicaragua, Noviembre 2006. http://www.inide.gob.ni/censos2005/VolPoblacion/Volumen Poblacion1-4/Vol.I Poblacion-Caracteristicas Generales.pdf 
Chorotega-Nahua-Mange. Estas cifras muestran claras discrepancias con otros estudios, ${ }^{1}$ ya que una investigación realizada en el año 2000 por la Universidad de las Regiones Autónomas de la Costa Caribe Nicaragüense (URACCAN), en coordinación con los pueblos indígenas, presenta cifras muy superiores: los nahoa-nicarao o náhuatl, con 20.000 miembros; los Cacaopera o Matagalpa, con 97.500 miembros; los ocanxiu o sutiaba, con 49.000 miembros; y los Chorotega, con 221.000.

Nuevamente se pronuncia a este respecto el Comité para la Eliminación de la Discriminación Racial de Naciones Unidas, en marzo del 2008, invitando al estado nicaragüense, entre otras cosas, a la incorporación y consideración de estos pueblos en las políticas de estado; así como la adopción de una ley especifica que reconozca y proteja los derechos de los pueblos Indígenas del Pacifico, Centro y Norte; tal y como lo mandata la Convención Internacional sobre la Eliminación de Todas las Formas de Discriminación Racial. ${ }^{3}$

Textualmente, cuando el Comité se refiere a la necesidad de una ley para pueblos indígenas del Pacifico, Centro y Norte expresa:

15.-...Al Comité le preocupa que los pueblos indigenas de la zona del Pacifico, Centro y Norte de Nicaragua no gocen de una ley especifica que reconozca y proteja sus derechos. El Comité exhorta al Estado parte a que acelere el proceso de adopción de la Ley General de Pueblos Indígenas del Pacifico, Centro y Norte de Nicaragua...4

Sin embargo, desde hace más de cinco años se encuentra ante la Comisión Permanente de Asuntos Étnicos, Regímenes Autonómicos y Comunidades Indígenas de la Asamblea Nacional, el anteproyecto de ley para regular el régimen jurídico de los pueblos indígenas del Pacífico, Centro y Norte de Nicaragua. Y a pesar que la misma Asamblea Nacional aprobó el 11 de marzo del 2008 la DECLARACIÓN A.N. No. $001-2008^{5}$ refiriéndose expresamente al contenido de la Declaración de las Naciones Unidas sobre los Derechos de los Pueblos Indígenas, donde La Asamblea Nacional "asume el compromiso de impulsar acciones que retomen las premisas jurídicas de la Declaración de las Naciones Unidas sobre los Derechos de los Pueblos Indígenas para adecuar los marcos normativos nacionales". Aun a la fecha, los representantes del pueblo nicaragüense en la Asamblea Nacional no han decidido reivindicar los derechos de estos pueblos y comunidades aprobando la ley; al contrario, con tal omisión han discriminado a los pueblos indígenas del Pacifico, Centro y Norte, al ser éstos el único sector social fácilmente diferenciable, en Nicaragua, que no cuenta con una ley para regular su situación jurídica; mientras los pueblos indígenas y comunidades afro descendientes de la Costa Atlántica de Nicaragua sí cuentan con legislación pertinente.

\section{EI Derecho a la libre determinación}

La Declaración de las Naciones Unidas sobre los Derechos de los Pueblos Indígenas, aprobada en el seno de las Naciones Unidas con el voto del Estado de Nicaragua, en septiembre del año 2007, y respaldada por la Asamblea Nacional en Declaración del 11 de marzo del 2008, en su artículo 3 reconoce el derecho de libre determinación a los pueblos indígenas. ${ }^{6}$ Lo que naturalmente comprende a los pueblos indígenas del Pacifico, Centro y Norte de Nicaragua. El derecho de libre determinación de los pueblos o derecho de autodeterminación, es el derecho de un pueblo a decidir sus propias formas de gobierno interno, perseguir su desarrollo económico, social y cultural desde su propia cosmovisión, y organizarse libremente, según sus propios usos y costumbres; así como, también, que sus miembros cuenten con una nacionalidad y a no ser objeto de asimilación forzada.

\footnotetext{
2 “...el Comité observa las deficiencias del Censo Nacional de la Población de 2005, el cual no permitió determinar con precisión las características de los diferentes grupos étnicos y pueblos indígenas que componen la población nicaragüense, incluidos aquellos que resultan de una mezcla de culturas". Observaciones finales del Comité para la Eliminación de la Discriminación Racial. Nicaragua. Examen de los Informes Presentados por los Estados Parte de conformidad con el Arto. 9 de la Convención Internacional sobre la Eliminación de Todas las Formas de Discriminación Racial (CERD). CERD/C/NIC/CO/14 de marzo de 2008 (En adelante Informe CERD).

3 20.-...El Comité recuerda al Estado parte su Recomendación general $N^{\circ} 23$ (1997) sobre los derechos de los pueblos indigenas aparatado (d), párrafo 4(1) y recomienda que redoble sus esfuerzos para asegurar la plena participación de los pueblos indígenas y comunidades afro descendientes en los asuntos públicos del Estado a todos los niveles. Informe CERD.

Observación No. 15. Informe CERD.

Publicada en La Gaceta, Diario Oficial No 68 del 11 de abril del 2008.

6 Artículo 3.- Los pueblos indigenas tienen derecho a la libre determinación. En virtud de ese derecho determinan libremente su condición política y persiguen libremente su desarrollo económico, social y cultural.
} 


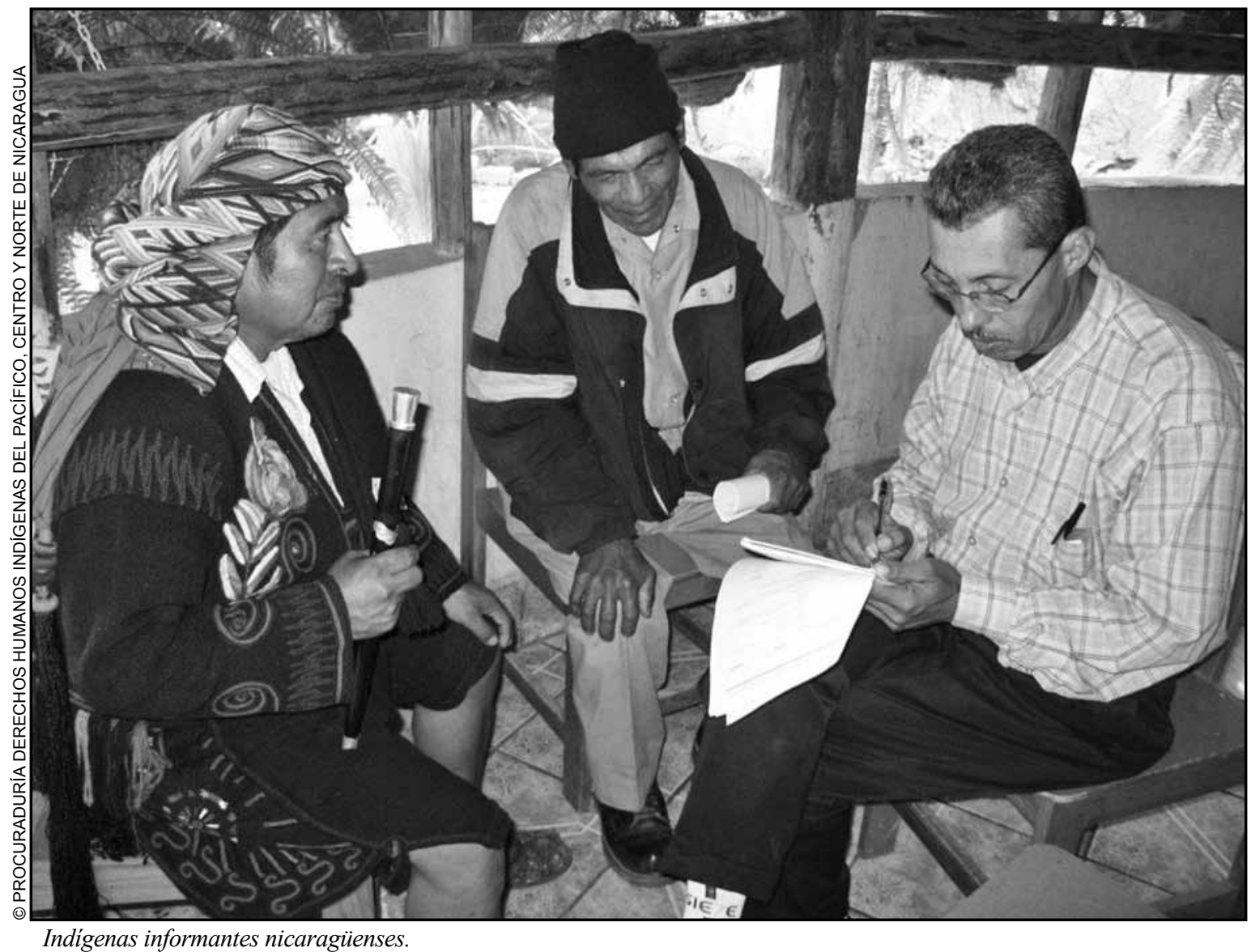

Este derecho a la libre determinación para los pueblos indígenas incluye el de ser tratados, principalmente por los estados de los que forman parte, bajo el principio de igualdad. La autodeterminación es uno de los derechos fundamentales de los pueblos conforme al derecho internacional, y está recogido en los documentos más importantes tales como la Carta de las Naciones Unidas o los Pactos Internacionales de Derechos Humanos. También, numerosas resoluciones de la Asamblea General de la ONU hacen referencia a este principio y lo desarrollan. Es un principio fundamental del Derecho Internacional Público y un derecho de los pueblos que tiene carácter inalienable y genera obligaciones ${ }^{[]}$para todos los Estados.

\section{EI Sistema Interamericano para la Protección de los Derechos Humanos}

Normas internacionales, como el Pacto Internacional de Derechos Económicos, Sociales y Culturales, el Pacto Internacional de Derechos Civiles y Políticos de la Organización de las Naciones Unidas, y la Convención Americana de Derechos Humanos de la Organización de Estados Americanos (en adelante la Convención Americana), conforman parte del ordenamiento jurídico nicaragüense, según lo establece expresamente el artículo 46 de la Constitución Política de Nicaragua. La Declaración de las Naciones Unidas sobre los Derechos de los Pueblos Indígenas y el Convenio 169 de la OIT sobre Pueblos Indígenas y Tribales en Países Independientes, ${ }^{7}$ son instrumentos aplicados insistentemente por el Sistema Interamericano para la Protección de los Derechos $\mathrm{Hu}-$ manos de la Organización de Estados Americano (OEA) (en adelante el Sistema Interamericano) conformado por la Comisión y la Corte Interamericano de Derechos Humanos de la Organización de Estados Americanos (en adelante la Comisión Interamericana o la CIDH y la Corte Interamericana o la Corte IDH) .

El caso de la Declaración de las Naciones Unidas sobre los Derechos de los Pueblos Indígenas es muy particular, en el sentido que las declaraciones del sistema de Naciones Unidas no han sido tradicionalmente vinculantes; esta Declaración, en cambio, contiene un mandato especifico, no solo de promover su plena aplicación, sino la designación 
de los órganos que se encargarán de hacerlo; la Declaración establece en su Artículo 42:

Las Naciones Unidas, sus órganos, incluido el Foro Permanente para las Cuestiones Indigenas, y los organismos especializados, en particular a nivel local, así como los Estados, promoverán el respeto y la plena aplicación de las disposiciones de la presente Declaración y velarán por la eficacia de la presente Declaración.

De esta manera, la Declaración de las Naciones Unidas sobre los Derechos de los Pueblos Indígenas se convierte en un instrumento internacional vinculante, aplicable de manera práctica para los estados miembros de las Naciones Unidas, al otorgarle la misma Declaración a los órganos de Naciones Unidas, así como a los Estados, el deber de promover "...el respeto y la plena aplicación de las disposiciones y la eficacia de la Declaración". Por lo que la Corte Interamericana ha venido aplicando en diferentes casos la Declaración desde su aprobación.

Pero aun antes de ser aprobada la Declaración de las Naciones Unidas sobre los Derechos de los Pueblos Indígenas, el Sistema Interamericano ya se había pronunciado tres veces sobre los derechos de los pueblos indígenas de Nicaragua. Primeramente en la década de los años $80^{8}$; y recientemente en los casos de la comunidad mayangna (sumo) de Awas Tingni ${ }^{9}$ y sobre la organización política indígena "Yapti Tasba Masraka Nanih Asla Takanka" (Hijos de la Madre Tierra) denominada por sus siglas como YATAMA. ${ }^{10}$ De esta forma, el Sistema Interamericano afirma, en sus procedimientos y sentencias, los derechos culturales, políticos y de propiedad sobre las tierras colectivas o comunales de estos pueblos y comunidades indígenas de Nicaragua.

La Convención Americana ha sido aplicada por la Comisión y la Corte Interamericana, en lo referente a las tierras indígenas de estos pueblos. La CIDH ha establecido claramente que los estados miembros de la OEA deben respetar y garantizar las tradiciones culturales de las comunidades indígenas. La CIDH se pronunció, en 1983, durante los enfrentamientos armados entre los pueblos indígenas de la Costa Atlántica, principalmente de origen miskito, y el gobierno sandinista. $Y$ en el año 1984, el Estado de Nicaragua asume un acuerdo de solución amistosa con estos pueblos y reconoce a los pueblos indígenas los derechos ancestrales sobre sus tierras y cultura; derechos que les fueron reconocidos posteriormente en la Constitución Política de Nicaragua de 1987.

La Corte Interamericana de Justicia en la Sentencia respecto a la comunidad mayangna (sumo) de Awas Tingni en el año 2001 considera que cuando el Arto. 21 de la Convención Americana establece que "toda persona tiene derecho al uso y goce de sus bienes", éste "protege el derecho de la propiedad en un sentido que comprende, entre otros, los derechos de los miembros de las comunidades indígenas en el marco de la propiedad comunal, la cual también está reconocida en la Constitución Política de Nicaragua" ". Ya que los indígenas poseen la tierra de manera colectiva, de forma que la pertenencia no se centra en el individuo sino en la comunidad, la estrecha relación que tienen los indígenas con sus tierras constituye "la base fundamental de sus culturas, su vida espiritual, su integridad, y su supervivencia económica. Para las comunidades indígenas, la relación con la tierra no es meramente cuestión de posesión o producción; sino un elemento material y espiritual del que deben gozar plenamente, inclusive, para preservar su legado cultural y transmitirlo a las generaciones futuras". ${ }^{12}$

El caso de YATAMA vs. Nicaragua en el año 2005 se origina por la decisión del Consejo Supremo Electoral de excluir al partido indígena YATAMA de las elecciones regionales. En la sentencia, la Corte Interamericana sigue la misma línea de pensamiento de la Convención Americana

\footnotetext{
8 Informe sobre los Derechos Humanos de un Sector de la Población Nicaragüense de Origen Miskito, OEA/Ser.L/V/II/.62 doc. 10 rev. 3, 20 noviembre 1983. Resolución sobre el Procedimiento de Soluciones Amistosas sobre la Situación de los Derechos Humanos de un Sector de la Población Nicaragüense de Origen Miskito. OEA/Ser.L/V/II.62 doc. 26, 16 mayo 1984.

9 Sentencia de la Corte Interamericana de Derechos Humanos en el caso de la Comunidad Mayagna (Sumo) de Awas Tingni Vs. Nicaragua del 31 de agosto 2001.

10 Sentencia de la Corte Interamericana de Derechos Humanos en el caso de la Comunidad Mayagna (Sumo) de Awas Tingni Vs. Nicaragua del 31 de agosto 2001.

11 Párrafo 148 de la Sentencia de la Corte IDH en el caso de la comunidad indígena mayagna (sumo) de Awas Tingni vs. Nicaragua del 31 de agosto 2001.

12 Ídem. Párrafo 149.
} 


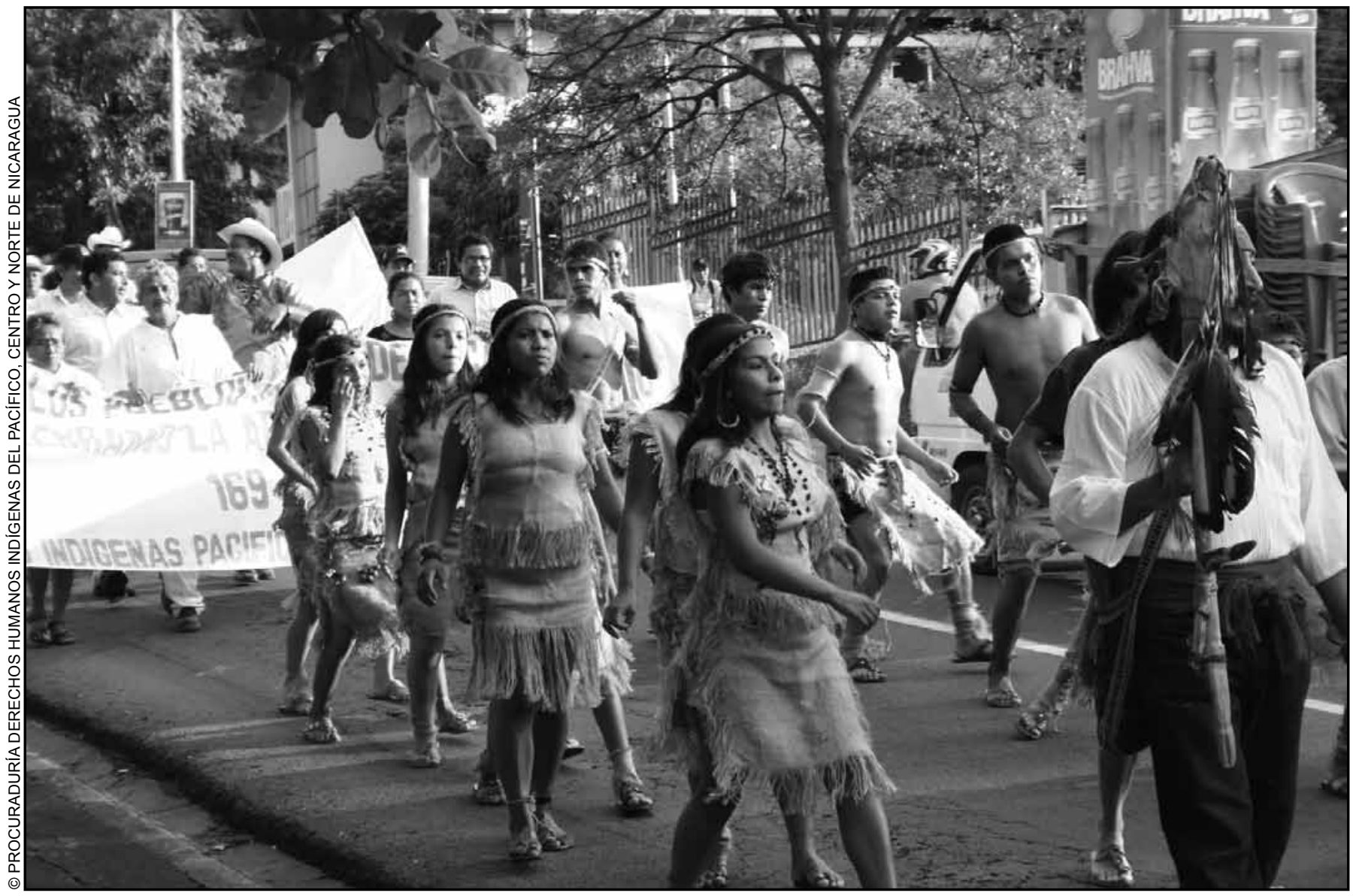

Indigenas del Norte de Nicaragua desfilando con sus trajes típicos.

cuando afirma el derecho a la participación política de los pueblos indígenas, lo mismo que el contenido del Arto. 5 de la Declaración de las Naciones Unidas sobre los Derechos de los Pueblos Indígenas que reconoce a estos pueblos "su derecho a participar plenamente...en la vida politica, económica, social y cultural del Estado".

La Declaración de las Naciones Unidas sobre los Derechos de los Pueblos Indígenas es plenamente aplicable a los pueblos indígenas el Pacifico, Centro y Norte de Nicaragua. En su artículo 4, la Declaración reconoce como ejercicio del derecho de autodeterminación de los pueblos indígenas, "el derecho a la autonomía o el autogobierno en las cuestiones relacionadas con sus asuntos internos y locales, así como a disponer de los medios para financiar sus funciones autónomas".
Estas normas internacionales reconocen el derecho de administrar sus tierras y territorios a los pueblos indígenas, así como a auto gobernarse por medio de la elección de sus propias autoridades y representantes legales; y son plenamente consistentes con lo establecido en el artículo 5 de la Constitución Política de Nicaragua.

La Constitución Política, la normativa internacional y varias leyes nacionales, algunas desde 1877, claramente señalan a los pueblos indígenas del Pacifico, Centro y Norte de Nicaragua las características por las cuales pueden ser considerados como entes jurídicos territoriales. Características tales como personería jurídica, autoridades o representantes legales propios, derechos sobre tierras y territorios, todo de conformidad con sus costumbres y tradiciones, debidamente diferenciadas de las del resto de la población nacional. ${ }^{13}$

13 Decreto Legislativo del 17 de mayo de 1877, Publicado en La Gaceta de Nicaragua, Managua, sábado 19 de mayo de 1887. Año XV, número 20, páginas 164 y 165. Sobre Venta de Terrenos Ejidales y de las comunidades indígenas. Menciona ya a las comunidades indígenas como dueñas de tierras. 


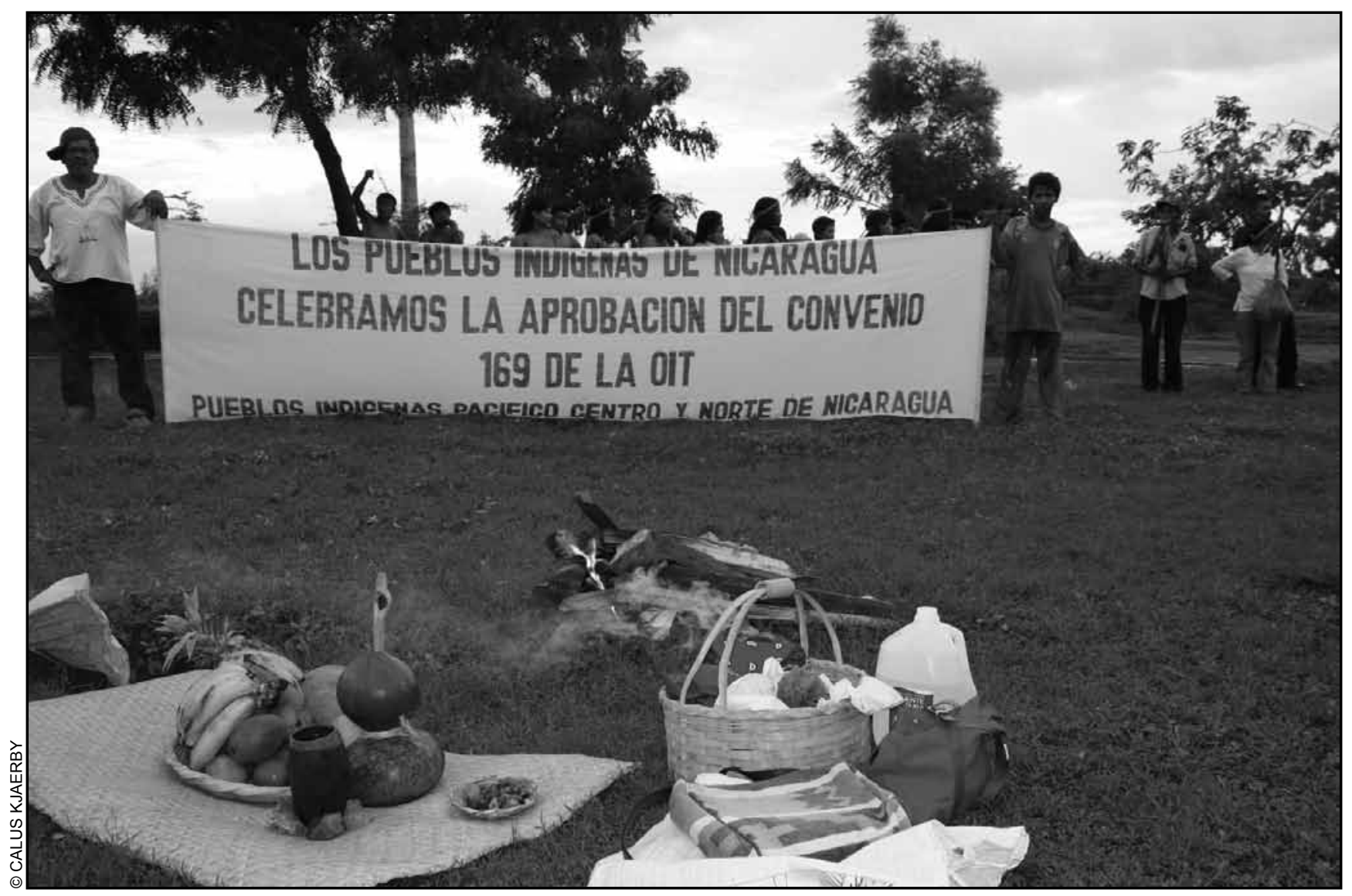

Indígenas del Norte de Nicaragua celebrando el reconocimiento de la Ley 169 por parte del gobierno nicaragüense.

\section{La Constitución Política de Nicaragua}

A partir de la reforma constitucional de 1995, por primera vez se reconoce la existencia de los pueblos indígenas en Nicaragua sin diferenciar a los pueblos indígenas de la Costa Atlántica o del Caribe, de los del Pacífico, Centro y Norte del país. Sin embargo, hasta entonces coexistieron dos regímenes legales bien diferenciados, uno para los pueblos indígenas y comunidades étnicas o afro descendientes de la Costa Atlántica; y el otro, para las comunidades indígenas del Pacífico, Centro y Norte del país.

Esta dicotomía de regímenes tiene origen en los diferentes desarrollos históricos de estos pueblos con relación el Estado Nacional. Las comunidades indígenas del Pacífico, Centro y Norte del país resistieron todo el proceso de conquista y colonización española y la posterior imposición del Estado Nacional sobre sus instituciones, teniendo como consecuencia la pérdida de la mayor parte de sus tierras y lenguas. En cambio, las comunidades indígenas de la Costa Caribe nunca fueron conquistadas por los españoles. La Mosquitia se convirtió en un protectorado inglés que permaneció bajo la influencia británica por más de un siglo, gobernado bajo un régimen de autonomía municipal hasta su incorporación al territorio nacional en $1894 .{ }^{14}$

La reforma constitucional de 1995, sin embargo, extendió el reconocimiento de pueblos indígenas a las comunidades indígenas del Pacifico, Centro y Norte del país, reconociendo expresamente su existencia como pueblo indígena, sin hacer distinción alguna con los pueblos indígenas y comunidades afro descendientes del Caribe nicaragüense. Hasta entonces, solamente los pueblos indígenas y comunidades étnicas de la Costa Caribe de Nicaragua habían sido reconocidas

14 “Incorporación”, para los habitantes del Caribe nicaragüense que sostienen que La Costa Atlántica nunca antes estuvo sometida a Nicaragua; "Reincorporación”, para los que sostienen que sí. Para conocer más sobre el tema ver: Rossbach, Lioba y Wunderich, Valker. “Derechos Indígenas y Estado Nacional en Nicaragua: La Convención Mosquita de 1894”. La Universidad; Revista de la Universidad Autónoma de Nicaragua, Managua. Vol. 2- No.7 Julio-Diciembre 1993. 
expresamente cómo "comunidades de la Costa Atlántica" en la Constitución Política de Nicaragua emitida en 1987; mientras los pueblos indígenas del Pacifico, Centro y Norte continuaron siendo excluidos por la misma Constitución, y legalmente seguían siendo tratados como simples dueños de tierras colectivas, en comunidad de bienes, regulada por el Código Civil de Nicaragua. Y sobre tal premisa se había legislado entre 1877 y 1952, teniendo como resultado la negación de las autoridades tradicionales indígenas y el despojo de las tierras comunales para los pueblos y comunidades del Pacifico, Centro y Norte de Nicaragua. Legislación que alcaldes, Ministerio de Gobernación y algunos jueces pretenden todavía imponer, a pesar de que después de la reforma constitucional de 1995 se convirtió en inconstitucional.

Es por eso que los pueblos y comunidades del Pacifico, Centro y Norte de Nicaragua reclaman en este momento una efectiva protección estatal, por medio de la elaboración de una ley que expresamente derogue la discriminatoria e inconstitucional legislación emitida por el Estado principalmente entre 1877 y 1952.

\section{La Legislación Inconstitucional}

A pesar de que los decretos y ordenanzas reales emitidas por los reyes de España reconocían la propiedad comunal en las
Leyes de Indias; ${ }^{15}$ los pueblos indígenas fueron exterminados y sus tierras usurpadas una vez constituidos los estados nacionales. También, los pueblos indígenas fueron sometidos a la aplicación de políticas de asimilación forzosa por medio de decretos que desmembraban las tierras comunales o las expropiaban, ya que la visión estatal imperante en la época era que las comunidades indígenas eran sociedades de transición hacia la cultura mestiza dominante y, por lo tanto, un retraso al "desarrollo" de la cultura homogénea que se pretende imponer.

Con esa misma línea de pensamiento derivada de las políticas gubernamentales de la época, el Estado de Nicaragua emitió, entre 1877 y 1952, las leyes y decretos legislativos que acabaron con gran parte de la propiedad indígena. ${ }^{16}$ Negaron a las comunidades indígenas su calidad de instituciones socioculturales y políticas diferenciadas e impusieron procedimientos extraños a las comunidades reduciéndolas a simples dueñas y administradoras de tierras. ${ }^{17}$ Desconocieron así todo status legal a sus autoridades comunales tradicionales e impusieron sobre ellas el poder político y administrativo del Estado nacional por medio de jefes políticos, juntas municipales y alcaldes.

El Estado nicaragüense entonces se muestra ambivalente ante la resistencia de estos pueblos y comunidades. Por una parte expropia la tierra indígena ${ }^{18}$, y por otra reconoce planes de

15 La Ley de Indias, Ley XIV, Libro IV expresa: "Ordenamos que la venta, beneficio y composición de tierras se haga con tal atención a que a los indios se les dé con sobra todas las que les pertenecieren, asi en particular como por COMUNIDADES y las aguas y riegos; y las tierras en las que hubieren hecho acequias y otro cualquier beneficio con que por industria personal suyas se hayan fertilizado; se reserve, en primer lugar, y por ningún caso no se les pueda vender, ni enajenar; y los jueces que a esto fueren enviados, especifiquen los indios que hallaren en las tierras y las que dexaren, a cada uno de los tributarios viejos, reservados, Caciques, gobernadores, ausentes y comunidades".

16 Decreto Legislativo del 17 de mayo de 1877 sobre venta de terrenos ejidales y los de comunidades indígenas derogado el 5 de marzo de 1881 publicado en La Gaceta del año XV, número 20 del 19 de mayo de 1877, páginas 164 y 165. Decreto Legislativo del 5 de marzo de 1881 sobre venta de terrenos ejidales y los de comunidades indígenas publicado en La Gaceta del año XIX, número 11 del 19 de marzo de 1881, página 81. Decreto Legislativo del 8 de marzo de 1895 que reglamenta la relación entre los comuneros, publicado en La Gaceta del año I, número 119 del 22 de marzo de 1895, pagina 2. Decreto Ejecutivo del 19 de marzo de 1895 que dispone que los jefes políticos den cumplimiento a la ley del 5 de marzo de 1881 publicado en La Gaceta del año I, número 127 del 2 de abril de 1895, páginas 2 y 3. Decreto Legislativo del 16 de febrero de 1906 sobre comunidades indígenas: derogados por la ley del 3 de junio de 1914. Declarado vigente por la ley del 24 de abril de 1918 en lo que respecta a la venta y arriendo de terrenos ejidales publicado en La Gaceta del año X, número 2745 del 21 de febrero de 1906, páginas 2 y 3. Decreto Ejecutivo del 20 de febrero de 1908 sobre personería de las comunidades indígenas publicado en La Gaceta del año XII, Tomo I, número 25, páginas 382 y 383. Decreto Legislativo del 3 de junio de 1914, que deroga el del 16 de febrero de 1906 sobre venta de terrenos de comunidades indígenas y reglamenta la administración de dichas comunidades, publicado en La Gaceta del año XVIII, número 125 del 6 de junio de 1914 , páginas 1 y 2. Decreto Legislativo del 6 de agosto de 1918, sobre Estatuto de Comunidades Indígenas, publicado en La Gaceta del año XXII, numero 182 dell4 de agosto de 1918, páginas 1457 a 1461. Decreto Ejecutivo de 10 de marzo de 1952, sobre Elecciones de las Juntas de Administración de los Bienes de las Comunidades Indígenas, publicado en La Gaceta, del 11 de marzo de 1952.

17 Acuerdo Ejecutivo del 16 de enero de 1925, que aprueba los Estatutos a la Comunidad Indígena de Sébaco, Departamento de Matagalpa.

18 Decreto No.41, Decreto Legislativo del 23 de diciembre de 1919 declarando de utilidad pública 1,000 hectáreas de terreno perteneciente a la Comunidad Indígena de Sébaco localizada en San Isidro, Departamento de Matagalpa. 


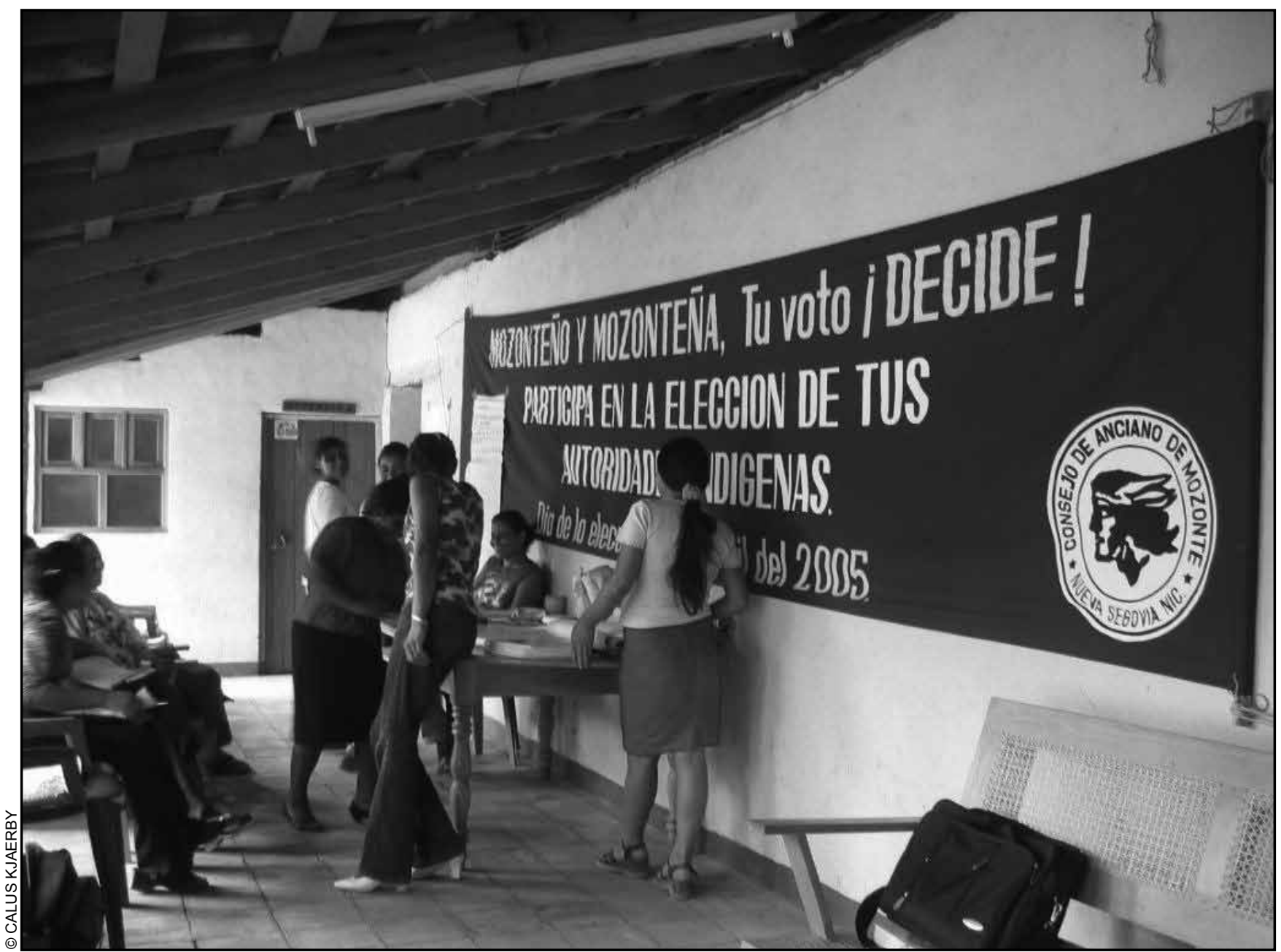

Indígenas del Norte de Nicaragua, participando en las elecciones indígenas. Mozonte 2010.

arbitrio a algunas comunidades para la administración de sus tierras $1^{9}$. También legisla prohibiendo a las municipalidades continuar la venta de la propiedad comunal indígena ${ }^{20}$.

Por ejemplo; El Decreto Legislativo del 17 de mayo de 1877 emitido por el Presidente don Pedro Joaquín Chamorro, ordena la destrucción de los ejidos y la expropiación a las comunidades indígenas sobre sus tierras comunales. Los artículos 1 y 2 del Decreto a expresan:

"Los poseedores o arrendatarios de terrenos de Ejidos, Comunes y de Comunidades Indígenas, que las hubieren acotado y cultivado, poseyéndolas por más de un año, tendrán derecho a que se les dé en propiedad, la parte en que hubieren verificado dicho cultivo...Los demás terrenos Ejidos, Comunes o de Comunidades Indigenas, que no estén comprendidos en el anterior artículo, serán puestos a la venta en licitación entre los vecinos o miembros de la comunidad por lotes que no excedan de diez manzanas en terrenos para agricultura y de cien las de crianza de ganado”.

Ésta y otras leyes de la época establecían términos extremadamente cortos para que las comunidades indígenas se constituyeran en personas jurídicas de conformidad con las leyes creadas específicamente para ello. Las consecuencias fueron entonces que las comunidades indígenas que no se constituyeron oficialmente en personas jurídicas perdieran sus territorios.

19 Acuerdo Ejecutivo del 13 de junio de 1924, por el que se aprueba el Plan de Arbitrios de la Comunidad Indígena de Muy Muy, Departamento de Matagalpa.

20 Decreto Legislativo del 26 de junio de 1935, que prohibe a las municipalidades las ventas de sus terrenos ejidales y los de Comunidades Indígenas, publicado en La Gaceta del año XXXIX, número 142 del 28 de junio de 1935, paginas 1129. 
Además, con el fin de institucionalizar la propiedad estatal, en 1904 se promulga el Código Civil, que en su artículo 614 expresa:

Son bienes del Estado, todas las tierras que, estando situadas dentro de los límites territoriales, carecen de otro dueño.

Entendiéndose como "dueño" el que ha inscrito la propiedad en el Registro Público de la Propiedad sin respetar el usufructo ancestral e histórico de estos pueblos y comunidades. Estableciendo con este artículo las bases jurídicas para la usurpación oficial de las tierras que habían estado hasta entonces bajo el dominio de las comunidades indígenas de Nicaragua, pero sin poseer título de propiedad.

Sin embargo, toda la legislación emitida entre 1877 y 1952 , a pesar de no haber sido derogada expresamente por otras leyes, al ser incompatible con lo preceptuado por el Arto. 5 de la Constitución Política de Nicaragua y con las normas internacionales citadas, especialmente con la Declaración de las Naciones Unidas sobre los Derechos de los Pueblos Indígenas, es actualmente inaplicable, como lo ha declarado la Corte Suprema de Justicia en varias sentencias.

\section{Las Municipalidades y las Comunidades Indígenas}

La forma más evidente de cómo los pueblos indígenas del Pacifico, Centro y Norte de Nicaragua perdieron la mayoría de sus tierras comunales fue con la creación de las municipalidades, al pasar sus tierras por ley a ser patrimonio de éstas. La legislación equiparó tierra ejidal y tierra comunal en muchas ocasiones. Lo que ha sido abolido por lo preceptuado en el párrafo 3 del Arto. 5 de la Constitución, ${ }^{21}$ la Ley de Municipios y su reforma ${ }^{22}$, cuando establecen expresamente en sus Artos. 67 a 69 que: "Los Municipios reconocerán la existencia de las comunidades indígenas ubicadas en sus territorios, legalmente constituidas o en estado de hecho...Asi mismo respetarán sus autoridades formales y tradicionales... Son autoridades tradicionales en las comunidades indígenas, aquéllas que se rigen por la tradición y la costumbre... cuya elección o nombramiento no tiene previsto un reglamento oficial". Y según la misma Ley de Municipios, el reconocimiento de las autoridades comunales "cuya elección o nombramiento no tiene

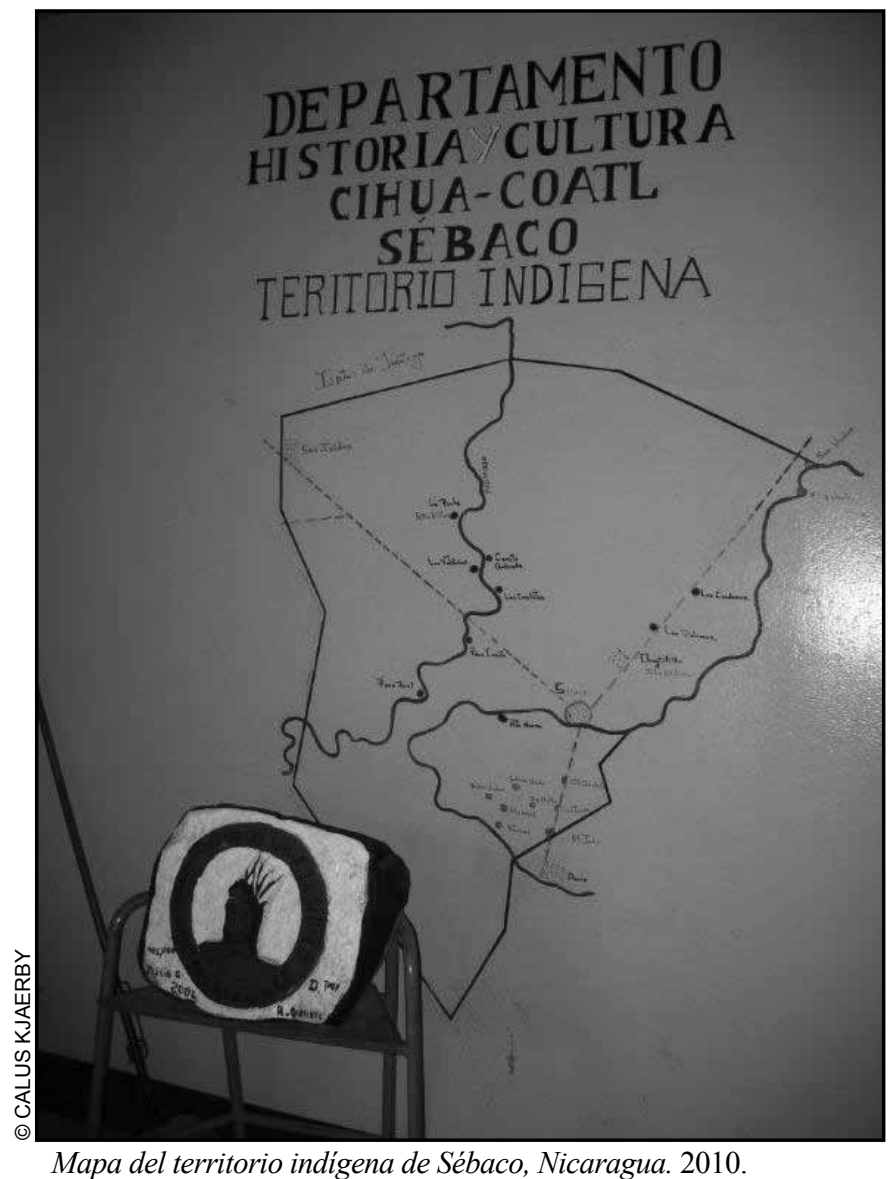

previsto un reglamento oficial" deben reconocerse al ser éstas consideradas como autoridades comunales por las características propias de sus costumbres y tradiciones.

Así mismo, cuando la Ley de Municipios cita las leyes indígenas de 1914 y 1918 en el Arto. 67, bajo el Capítulo II "De los Municipios con Pueblos Indígenas en su Territorio" refiriéndose a los municipios del Pacífico, Centro y Norte, estas normas ya han sido derogadas tácitamente en lo que se oponen a lo establecido en el párrafo 3 del artículo 5 de la Constitución Política de Nicaragua, al ser ésta una norma de mayor jerarquía y haber sido emitida posteriormente a la fecha de emisión de las leyes indígenas de 1914 y 1918, por lo que no pueden ser aplicadas actualmente.

Consistentemente, el artículo 177 de la Constitución Política de Nicaragua establece expresamente la relación que debe existir entre las municipalidades y los pueblos indígenas.

\footnotetext{
21 El párrafo 3 del Arto. 5 expresa: "El Estado reconoce la existencia de los pueblos indigenas, que gozan de los derechos, deberes y garantías consignados en La Constitución, y en especial los de mantener y desarrollar su identidad y cultura, tener sus propias formas de organización social y administrar sus asuntos locales, así como mantener las formas comunales de sus tierras y el goce, uso y disfrute de las mismas..."

22 Ley 40 Publicado en La Gaceta, Diario Oficial No. 155 de 17 de agosto de 1988 y Ley 261, 22 de agosto de 1997.
} 


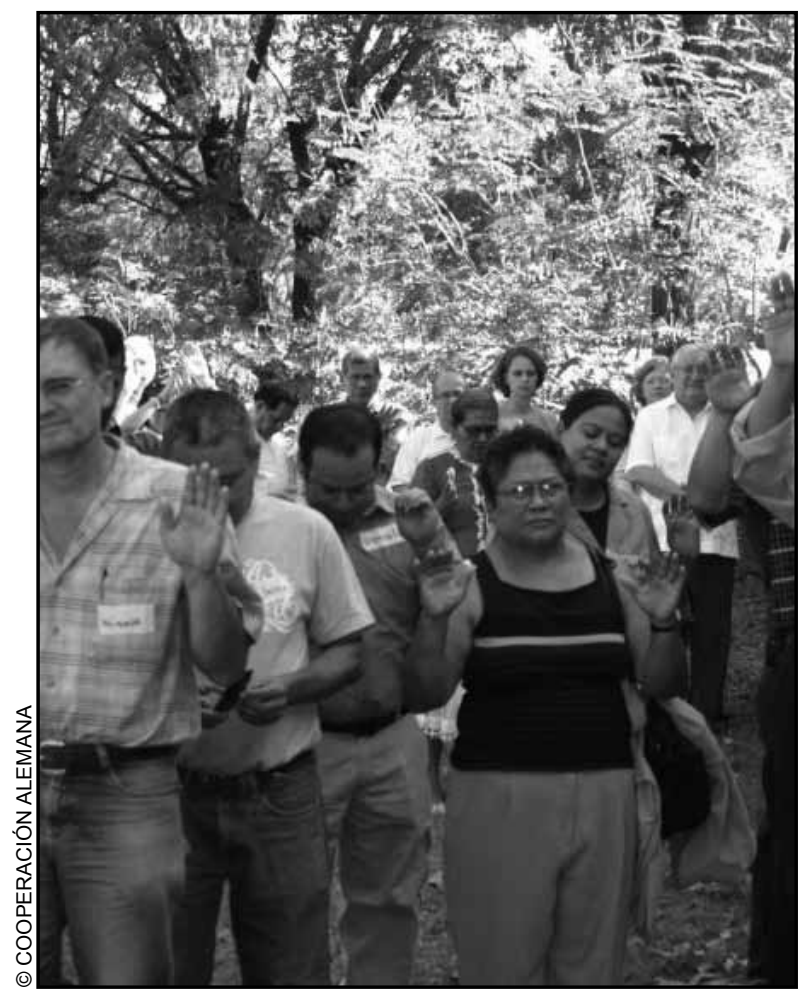

Indigenas del Norte, Centro y Pacifico de Nicaragua, durante un taller. Los acompaña la Dra. Mirna Cunningham. Enero 2010.

El Arto. 177 in fine, establece: ..."La Ley de Municipios deberá incluir, entre otros aspectos, las competencias municipales, las relaciones con el gobierno central, con los pueblos indígenas de todo el país y con todos los poderes del Estado, y la coordinación interinstitucional". Estableciendo de esta manera las bases para una nueva relación jurídica entre las comunidades y pueblos indígenas, y las municipalidades, en las que cada una conserva su autonomía, y en la cual a los pueblos indígenas se les garantiza el derecho a "tener sus propias formas de organización social y administrar sus asuntos locales”, dejando atrás la sujeción de los pueblos indígenas a la municipalidad, que establecía la legislación emitida entre 1877 y 1952.

\section{La Jurisprudencia}

La autonomía indígena ha sido reafirmada por la Sala Constitucional de la Corte Suprema de Justicia de Nicaragua en la sentencia 101 del veintiséis (26) de agosto del dos mil cuatro (2004), a las diez y cuarenta y cinco minutos de la mañana (10:45 a.m.), cuando resolvió un Recurso de Amparo presentado por la comunidad indígena de Sébaco, declarando inconstitucional el Decreto 491 del 11 de marzo de 1952. El Decreto 491 instituía que "la convocatoria, organización, tramitación, autorización, escogencia y nombramiento del Directorio que recibirá la votación, el escrutinio y el resultado final de la elección de la Junta de las Comunidades Indigenas estaba a cargo del Alcalde municipal", lo que declara inaplicable la Corte no solo en esta sentencia sino que en alrededor de diez sentencias más emitidas hasta la actualidad.

La Corte establece que el alcalde al invocar el Decreto 491 se excede en sus funciones, "al no estar ya dentro de sus facultades..." la organización de las elecciones comunales dentro de sus jurisdicciones municipales, porque de ninguna manera en la Ley de Municipios vigente se le concede al alcalde o al concejo municipal la facultad de convocar, organizar y celebrar las elecciones de la junta directiva de las comunidades indígenas, ya que lo establecido por el párrafo 3 del Arto. 5 y 177 de la Constitución, la actual Ley de Municipios, en su artículo 69 expresa: "Corresponderá a los Concejos Municipales respectivos de conformidad con las leyes de la materia, asegurar, reconocer y certificar la elección de las autoridades comunitarias de las comunidades ubicadas en el ámbito territorial del Municipio", por lo que la Corte establece que las municipalidades quedan fuera de las elecciones de autoridades comunales, dándoles solo el papel de "asegurar, reconocer y certificar" las elecciones, pero desde fuera. De esta forma, la Corte reconoce que tales elecciones deben ser conducidas desde principio a fin por los pueblos indígenas según sus costumbres y tradiciones. Por lo que "asegurar" no puede significar de ninguna manera la injerencia municipal en el proceso electoral, ya que las autoridades municipales deben respetar la autonomía de las comunidades indígenas en todo su ámbito de actuación y competencia interna, como lo establece la misma Ley de Municipios, en su Arto,. 67.- " Los Municipios reconocerán la existencia de las comunidades indigenas ubicadas en sus territorios, legalmente constituidas o estado de hecho.... sean propietarias de terrenos comunales o no. Así mismo, respetarán a sus autoridades formales y tradicionales, a quienes deberán tomar en cuenta en los planes y programas de desarrollo municipal y en las decisiones que afecten directa o indirectamente a su población y territorio". Por lo que con la Sentencia 101, la Corte Suprema de Justicia de Nicaragua reiteró la supremacía de la Constitución sobre la legislación de 1877 a 1952 en la relación entre los pueblos indígenas del Pacifico, Centro y Norte y las municipalidades.

\section{La Ley para los Pueblos Indígenas del Pacifico, Centro y Norte}

Los pueblos indígenas del Pacifico, Centro y Norte de Nicaragua fueron invitados por la Comisión Permanente de Asuntos Étnicos, Regímenes Autonómicos y Comunidades Indígenas de la Asamblea Nacional, en el año 2005, a presentar un anteproyecto de ley para regular la situación jurídica de 
estos pueblos y comunidades. ${ }^{23}$ Pero una vez dictaminado el anteproyecto de ley, los señores diputados le introdujeron más de 40 mociones adicionales, convirtiendo la propuesta en un documento muy poco técnico, repetitivo y desordenado.

Pero el peor de los cambios introducidos al proyecto por la Asamblea Nacional es la creación de un Consejo de Pueblos Indígenas como "órgano superior" de los Pueblos Indígenas del Pacifico, Centro y Norte de Nicaragua. Con la creación de ese "órgano superior" estaríamos nuevamente ante una violación a la autodeterminación indígena por parte del Estado, superponiendo a los pueblos indígenas su autoridad; a pesar de que los pueblos indígenas, según la Constitución Política de Nicaragua, tienen el derecho de "tener sus propias formas de organización social y administrar sus asuntos locales...y a hacerlo "de conformidad con sus costumbres y tradiciones". Y, además, según el Artículo 4 de la Declaración de Naciones Unidas sobre Derechos de los Pueblos Indígenas, tienen derecho a la autonomía o el autogobierno en las cuestiones relacionadas con sus asuntos internos y locales, así como a disponer de los medios para financiar sus funciones autónomas. Faltando de esta forma la Asamblea Nacional a la protección legal de la autonomía indígena, que no es solamente una garantía Constitucional sino también un compromiso que ha adquirido el Estado de Nicaragua ante la comunidad internacional.

Los pueblos indígenas del Pacifico Centro y Norte consultaron el anteproyecto, actualmente en la Asamblea Nacional, a las autoridades y a los pueblos indígenas del Pacifico, Centro y Norte, los cuales le hicieron sus observaciones. De tales observaciones resultó, entre otras cosas, la eliminación del Consejo de Pueblos Indígenas en el Anteproyecto de Ley de Pueblos Indígenas del Pacifico Centro y Norte de Nicaragua. El Anteproyecto fue así entregado por los líderes indígenas, a finales del 2009, a la Comisión Permanente de Asuntos Étnicos, Regímenes Autonómicos y Comunidades Indígenas de la Asamblea Nacional, la cual no se ha pronunciado de forma alguna.

\section{Conclusiones}

La Constitución Política de Nicaragua y el derecho internacional protegen los derechos de los pueblos indígenas del Pacifico, Centro y Norte de Nicaragua, sin embargo, el Estado de Nicaragua no se decide a honrar su compromiso regulando de manera legislativa esa normativa, para de esta forma promover una efectiva protección a los derechos humanos de estos pueblos y comunidades; así como revertir la discriminación sistemática de que han sido objeto en Nicaragua.

Lo establecido en el párrafo 3 del artículo 5 de la Constitución Política de Nicaragua, plenamente consistente con las normas establecidas en la Declaración de Naciones Unidas sobre Derechos de los Pueblos Indígenas, debería ser suficiente protección para los pueblos indígenas del Pacifico Centro y Norte, ya que ninguna norma legal se puede aplicar cuando contradice la Constitución. Como lo ha declarado la Corte Suprema de Justicia estableciendo jurisprudencia a favor del derecho de los pueblos indígenas del Pacifico, Centro y Norte a nombrar autónomamente a sus autoridades frente a la injerencia municipal.

Pero una ley que expresamente derogue la legislación asimilacioncita y expropiadora elaborada entre 1877 y 1952 es recomendable, para asegurar la efectividad del régimen legal constitucional e internacional de los pueblos indígenas del Pacifico, Centro y Norte. Y, específicamente, para desterrar las ilegales y discriminatorias prácticas de las municipalidades, y de cualquier otra entidad estatal, en contra de la autonomía indígena y la protección a la propiedad colectiva de estas comunidades y pueblos.

Por lo que la Asamblea Nacional debe abrirse a la participación activa de los pueblos indígenas del Pacifico, Centro y Norte, por medio de la aceptación de los resultados de la consulta presentada por las autoridades indígenas; consulta que la Ley Orgánica de la Asamblea Nacional obliga realizar en el proceso de formación de las leyes. Y de esta manera aprobar la ley para regular el régimen legal de los pueblos indígenas del Pacifico, Centro y Norte, como se ha comprometido a hacerlo; no solamente ante los representantes de los pueblos indígenas, sino ante la comunidad internacional, por medio de la DECLARACIÓN A.N. No. 001-2008 en que "asume el compromiso de impulsar acciones que retomen las premisas jurídicas de la Declaración de las Naciones Unidas sobre los Derechos de los Pueblos Indígenas para adecuar los marcos normativos nacionales".

\footnotetext{
23 "Los suscritos Diputados miembros de la Comisión de Asuntos Étnicos y Comunidades Indígenas de la Asamblea Nacional de la República de Nicaragua se reunieron el día dos de Agosto del año dos mil seis, con el objeto de Dictaminar la Iniciativa de Ley General de Pueblos Indígenas, la misma fue presentada ante la Secretaria de la Asamblea Nacional el dieciséis de Julio del año Dos mil cuatro. Con fecha ocho de Septiembre de éste mismo año, en la continuación de la Tercera Sesión Ordinaria de la XX legislatura se acordó remitir a ésta comisión dicha iniciativa para su respectivo Dictamen".

Dictamen de la Comisión de Asuntos Étnicos y Comunidades Indígenas de la Asamblea Nacional.
} 